\title{
EFFECT OF DEEP AND QUIET BREATHING ON PULMONARY COMPLIANCE IN MAN * $\dagger$
}

\author{
By BENJAMIN G. FERRIS, JR. AND DAVID S. POLLARD \\ (From the Department of Physiology, Harvard School of Public Health, and Mary MacArthur \\ Respirator Unit, The Children's Medical Center, Boston, Mass.)
}

(Submitted for publication April 20,1959; accepted September 1, 1959)

Observations on convalescent patients with respiratory muscle paralysis due to poliomyelitis have shown that their lungs are approximately half as compliant as normal (1). A similar reduction in pulmonary compliance has been observed in patients under anesthesia (2). Other workers have reported that during the acute stages of poliomyelitis the compliance of the lungs and thorax decreased as the vital capacity decreased (3). Reduction in pulmonary compliance has been observed in anesthetized dogs and on excised dogs' lungs; such changes could be prevented if the lungs were occasionally stretched by means of a deep breath (4). The use of occasional deep breaths was recommended in one of the earliest reports on the treatment of patients with respiratory muscle paralysis (5) and clinical observations on the vital capacity of patients with moderate residual respiratory muscle weakness due to poliomyelitis have shown that the vital capacity is increased by a series of assisted maximal inspirations (6). Since the fall in compliance in patients with poliomyelitis has been observed to parallel the fall in vital capacity $(3,6)$ the question may be asked whether similar reductions in lung compliance occur in intact unanesthetized human beings when they breathe quietly. If similar changes occur it would be of interest to determine their magnitude, how quickly they develop and whether they could be reversed. It would also be pertinent to determine whether the decreased compliance observed in poliomyelitic patients could be increased. Such information would be useful to guide the treatment of patients who require prolonged artificial respiration, so that reductions in compliance might be minimized.

* Given in part at the Fourth International Poliomyelitis Congress.

$\dagger$ Aided by a grant from The National Foundation.

\section{METHODS}

Measurements were made on 11 adult convalescent poliomyelitic patients and 10 normal adults. The patients used a tank respirator since they had markedly reduced breathing capacities. The patients were studied from six months to three years after the onset of their acute illness.

Change in esophageal pressure obtained from a latex balloon approximately $15 \mathrm{~cm}$. in length and with the tip probably in the lower third ${ }^{1}$ of the thoracic esophagus was used as an index of change in pleural pressure (7). The pressure difference between the esophageal balloon and mouthpiece was measured by an inductance manometer, and was used to represent transpulmonary pressure. In most of the studies involving the patients, the pressure difference from the tank to the mouth was also measured and represented the pressure differences across the lungs and thorax. ${ }^{2}$ Volume changes were obtained from a closed circuit recording spirometer (modified Benedict-Roth) and recorded electrically by means of a rotating potentiometer. Airflow was measured by means of a pneumotachograph. Pressure, volume and flow changes were electrically amplified and recorded simultaneously on a multi-channel, direct-writing oscillograph

Pulmonary compliance was calculated as the ratio of change in volume to change in "transpulmonary" pressure at points of zero airflow during quiet breathing. An average value determined from at least 10 respiratory cycles was used to represent the lung compliance. In a similar manner the compliance of the lungs and "thorax" was measured in the patients, and the "thoracic" compliance was calculated. Respiratory frequencies ranged from 9 to 18 per minute, with the lower frequencies in the normal subjects.

It was recognized that the esophagus as a site for pressure recording was subject to considerable error especially in the supine position (8). Since direct intrapleural pressure measurements were not practical, the inherent variability of the esophageal site had to be accepted as a part of the variations in the data collected. To minimize

\footnotetext{
${ }^{1}$ The balloon on the end of a polyethylene catheter was passed through the nose. The distance from the tip of the balloon to the nares ranged from 35.5 to $45.5 \mathrm{~cm}$., depending upon the size of the subject.

2 Thorax here is used to include rib cage, diaphragm, and abdominal wall and abdominal contents.
} 
TABLE I

Patients

\begin{tabular}{|c|c|c|c|c|c|c|c|c|}
\hline Patient & Sex & Age & $\mathrm{Ht}$. & Wt. & $\begin{array}{l}\text { Supine } \\
\text { vital } \\
\text { capacity }\end{array}$ & $\begin{array}{l}\text { Supine } \\
\text { functional } \\
\text { residual } \\
\text { capacity }\end{array}$ & $\begin{array}{l}\text { supine } \\
\text { residual } \\
\text { volume }\end{array}$ & $\begin{array}{l}\text { Continuous unassisted } \\
\text { time per day }\end{array}$ \\
\hline & & yrs. & $\mathrm{cm}$ & $K g$. & $L$. & $L$ & $L$. & \\
\hline E. C. & $\mathbf{M}$ & 31 & 183 & 82.0 & 0.20 & 2.21 & 2.21 & $1-2 \mathrm{~min}$. \\
\hline J. G. & $\mathbf{F}$ & 23 & 160 & 43.0 & 0.35 & 1.80 & 1.80 & 4-5 min. \\
\hline P. G. & $\mathbf{F}$ & 21 & 157 & 29.0 & 0.58 & 2.59 & 2.59 & 8 hrs. \\
\hline M. H. & $\mathbf{F}$ & 30 & 167 & 39.5 & 0.27 & 1.34 & 1.34 & $\frac{1}{2} \mathrm{hr}$ \\
\hline N. H. & $\mathbf{M}$ & 19 & 183 & 53.0 & 1.10 & 2.51 & 2.40 & $10-12$ hrs. \\
\hline & $\mathbf{M}$ & 41 & 177 & 66.0 & 0.40 & 2.62 & 2.62 & without GPB $1 \mathrm{hr}{ }^{*}$ \\
\hline M. M. & $\mathrm{F}$ & 40 & 160 & 42.0 & 0.20 & 1.97 & 1.97 & $1-2 \mathrm{~min}$. \\
\hline E. R. & $\mathrm{F}$ & 29 & 162 & 51.0 & 0.22 & 2.03 & 2.03 & $1-2 \mathrm{~min}$. \\
\hline M. S. & $\mathrm{F}$ & 17 & 170 & 33.5 & 0.55 & 1.62 & 1.54 & 2-3 hrs. \\
\hline R. T. & $\mathrm{M}$ & 38 & 182 & 62.0 & 0.33 & 2.44 & 2.44 & $5-10 \mathrm{~min}$. \\
\hline W. W. & $\mathbf{M}$ & 16 & 180 & 44.0 & 0.24 & 1.60 & 1.60 & $5-6 \mathrm{~min}$. \\
\hline
\end{tabular}

${ }^{*} \mathrm{GPB}=$ glossopharyngeal breathing. With this type of respiration $\mathrm{H}$. J. could inflate his lungs to a volume of $1.90 \mathrm{~L}$. using 16 strokes. His continuous unassisted time could then be extended to six to seven hours.

variation in pressure measurements due to heart beats, a mean of the cardiac oscillations was estimated.

Measurements were made on the patients and subjects in the supine, lateral and prone positions. To examine whether changes occurred in the sitting position, the pulmonary compliance in the tidal volume range was measured at two lung volumes; one was the supine and the other the sitting functional residual capacity.

This was accomplished in the following manner: the supine resting end-expiratory position was monitored on a recording spirometer prior to position change and the oxygen consumption was approximately balanced by adding oxygen. Position change was accomplished by means of a tilting Gatch bed accompanied by appropriate adjustments to make a comfortable "chair." Any change in the resting end-expiratory position due to position change was recorded on the spirometer. To maintain a constant lung volume from the supine to the sitting position, an abdominal binder with inflatable balloon was used with

TABLE II

Normal subjects

\begin{tabular}{|c|c|c|c|c|c|c|c|}
\hline Subject & Sex & Age & Ht. & Wt. & $\begin{array}{c}\text { Supine } \\
\text { vital } \\
\text { capac- } \\
\text { ity }\end{array}$ & $\begin{array}{l}\text { Supine } \\
\text { func- } \\
\text { tional } \\
\text { residual } \\
\text { capac- } \\
\text { ity }\end{array}$ & $\begin{array}{c}\text { Supine } \\
\text { residual } \\
\text { volume }\end{array}$ \\
\hline $\begin{array}{l}\text { D. C. } \\
\text { R. D. } \\
\text { B. F. } \\
\text { R. F. } \\
\text { S. H. } \\
\text { A. J. } \\
\text { J. M. } \\
\text { D. P. } \\
\text { M. T. } \\
\text { N. W. }\end{array}$ & $\begin{array}{l}\text { M } \\
M \\
M \\
M \\
F \\
M \\
M \\
M \\
F \\
F\end{array}$ & $\begin{array}{r}y r s . \\
28 \\
41 \\
38 \\
33 \\
33 \\
32 \\
37 \\
33 \\
64 \\
33\end{array}$ & $\begin{array}{l}\mathrm{cm} . \\
184 \\
196 \\
188 \\
178 \\
155 \\
181 \\
187 \\
185 \\
162 \\
170\end{array}$ & $\begin{array}{l}\text { Kg. } \\
82.0 \\
81.6 \\
82.0 \\
82.0 \\
54.5 \\
71.5 \\
86.5 \\
66.0 \\
62.0 \\
55.0\end{array}$ & $\begin{array}{c}L . \\
5.52 \\
6.33 \\
5.80 \\
4.48 \\
3.05 \\
5.42 \\
6.00 \\
5.81 \\
2.30 \\
4.54\end{array}$ & $\begin{array}{c}L . \\
2.39 \\
3.90 \\
3.36 \\
3.26 \\
1.79 \\
2.94 \\
4.00 \\
3.45 \\
2.16 \\
3.86\end{array}$ & $\begin{array}{c}L . \\
1.54 \\
2.23 \\
2.12 \\
2.30 \\
1.28 \\
1.97 \\
2.63 \\
2.40 \\
1.75 \\
2.51\end{array}$ \\
\hline
\end{tabular}

pressure maintained while the subject was in the sitting position. No change in the resting end-expiratory position was recorded when the balloon was inflated beneath the binder as the subject was tilted into a sitting position.

When lung volume change was permitted to occur, no binder was used and gravity produced the lung volume change in the relaxed subject. The functional residual capacity (FRC) was measured in the supine position by means of the helium dilution method (9). Supine vital capacities and expiratory reserve volumes were obtained on the recording spirometer. All values were corrected to body temperature and pressure and saturated with water vapor (BTPS).

Deep breaths were achieved for the patients by increasing the negative tank pressures to 30 to $35 \mathrm{~cm} . \mathrm{H}_{2} \mathrm{O}$. Peak pressures were held for two to three seconds. The normal subjects inhaled spontaneously to their inspiratory limit. Pulmonary compliance was measured after completing a series of four maximally deep breaths, or after one or two deep breaths during the series. The purpose of the latter procedure was to determine whether there was a progressive change in compliance after each deep breath or whether one or two deep breaths produced most of the change. Compliance measurements were also made after a series of small, moderate and large increases in lung volume to observe whether or not there was a progressive increase in pulmonary compliance associated with progressively deeper breaths.

Following a series of deep breaths, quiet breathing was resumed. Patients breathed at their usual tank pressure and frequencies. The normal subjects breathed at a relatively constant and natural tidal volume. Esophageal pressures were monitored during the rest period to ensure that no deep breaths had been taken. The pulmonary compliance in the tidal volume range above the FRC was measured at intervals during the periods of quiet breathing. 


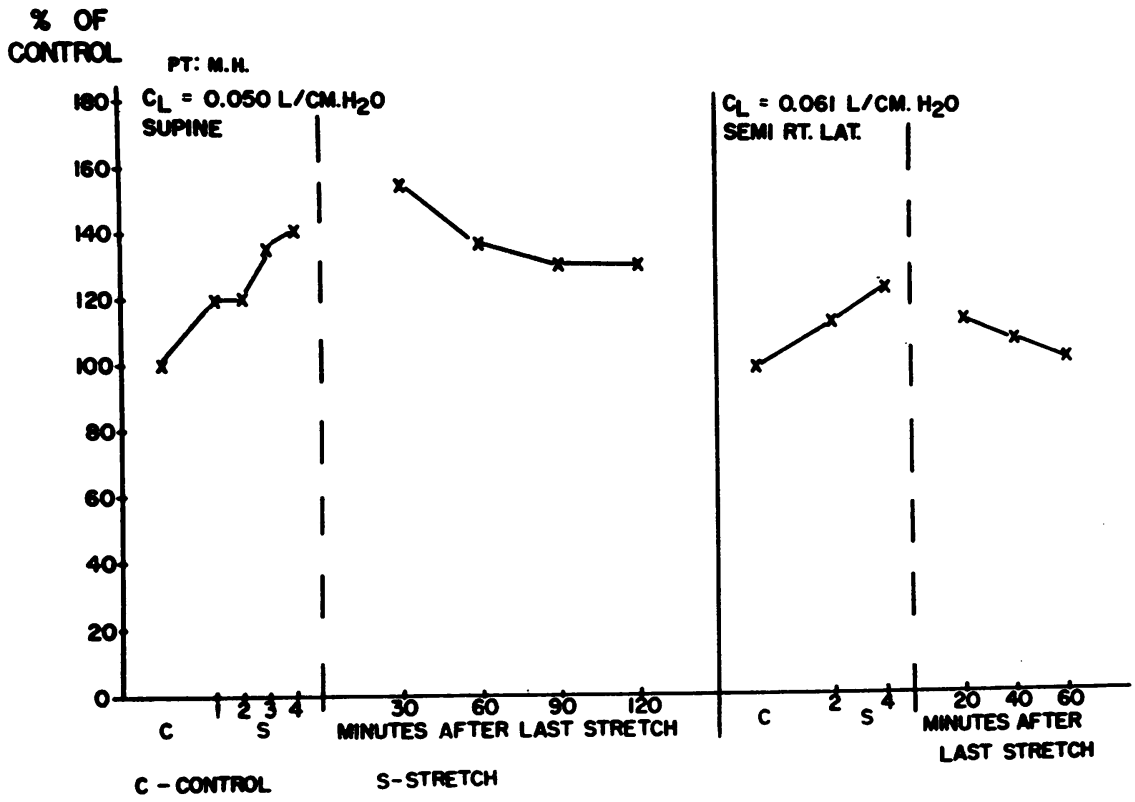

Fig. 1. Per Cent Change in Compliance of Lungs as Result of Deep and Shallow Breathing

RESULTS

The physical characteristics, vital capacity and spontaneous unassisted time of the patients are presented in Table $\mathrm{I}$, and those of the subjects in Table II.

Typical results obtained with a patient in supine and semi-right lateral position are presented in Figure 1 ; similar data obtained on a normal subject are shown in Figure 2. In both studies there was a marked increase in the pulmonary compli- ance as measured in the tidal volume range following deep breaths. In the normal subjects this change appeared to be complete after two deep breaths, whereas in the patients there was a progressive rise. During the period of quiet breathing both showed a fall of the compliance toward the control values, which was faster in the normal subjects than in the patients. The increase in compliance could be reproduced when another series of deep breaths was inhaled as shown in the subject in Figure 2.
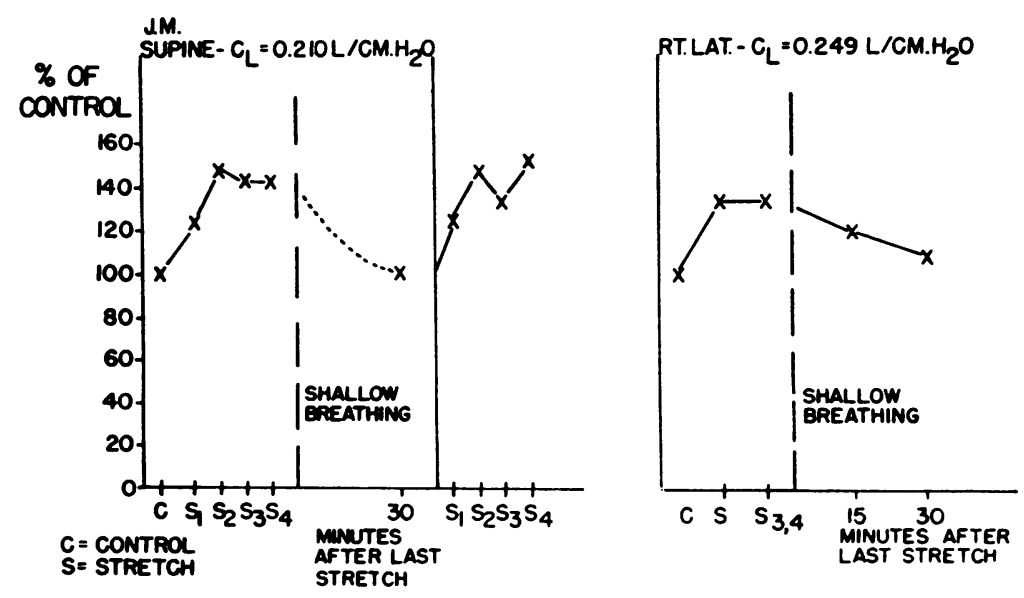

Fig. 2. Change in Compliance of Lungs as Result of Deep and. Shallow Breathing 
TABLE III *

Per cent change in compliance after deep breaths

\begin{tabular}{|c|c|c|c|c|c|c|}
\hline & & Supine & Lateral & Prone & $\underset{\text { (upright FRC) }}{\text { Sitting }}$ & $\begin{array}{c}\text { Sitting } \\
\text { (supine FRC) }\end{array}$ \\
\hline \multicolumn{7}{|l|}{ Patients } \\
\hline Lungs & $\begin{array}{l}\text { Mean } \\
\text { Range } \\
\text { n } \dagger\end{array}$ & $\begin{array}{c}29 \\
12 \text { to } 54 \\
23\end{array}$ & $\begin{array}{c}26 \\
11 \text { to } 49 \\
8\end{array}$ & $\begin{array}{c}40 \\
28 \text { to } 52 \\
2\end{array}$ & & \\
\hline $\begin{array}{l}\text { Lungs } \\
\text { and } \\
\text { "thorax" }\end{array}$ & $\begin{array}{l}\text { Mean } \\
\text { Range }\end{array}$ & $\begin{array}{l}17 \\
2.5 \text { to } 36.5 \\
23\end{array}$ & $\begin{array}{c}13 \\
11 \text { to } 14 \\
4\end{array}$ & $\begin{array}{c}22.5 \\
15 \text { to } 30 \\
2\end{array}$ & & \\
\hline "Thorax" & $\begin{array}{l}\text { Mean } \\
\text { Range } \\
n\end{array}$ & $\begin{array}{c}21 \\
-12 \text { to } 83 \\
23\end{array}$ & $\begin{array}{c}2 \\
-25.5 \text { to } 18 \\
4\end{array}$ & $\begin{array}{c}6.2 \\
4.5 \text { to } 8 \\
2\end{array}$ & & \\
\hline \multicolumn{7}{|c|}{ Normal subjects } \\
\hline Lungs & $\begin{array}{l}\text { Mean } \\
\text { Range } \\
\text { n }\end{array}$ & $\begin{array}{c}32 \\
5 \text { to } \\
9\end{array}$ & $\begin{array}{c}29 \\
5 \text { to } 49 \\
10\end{array}$ & $\begin{array}{c}29 \\
16 \text { to } 38 \\
4\end{array}$ & $\begin{array}{c}36 \\
26 \text { to } 45 \\
3\end{array}$ & $\underset{5}{20} \underset{\text { to }}{42}$ \\
\hline
\end{tabular}

* Data on which this table was compiled have been deposited as document number 6070 with the ADI Auxiliary Publications Project, Photoduplication Service, Library of Congress, Washington 25, D. C. Enclose remittance of $\$ 1.25$ per copy for a photoprint or a microfilm.

† $\mathrm{n}$ Represents the number of subjects. Where multiple studies were done in the same position on the same person, the average was used.

The average percentage change in compliance after deep breaths in the various body positions is presented in Table III. For the patients this change is shown for the lungs, lungs plus "thorax," and "thorax" alone. In each of the three positions studied-supine, lateral, ${ }^{3}$ and prone-there was an increase in the average pulmonary compliance. The range of increase obtained, however, was considerable. Similarly there was an increase in the compliance of the lungs plus "thorax." When the "thoracic" compliance was calculated the average increase in the supine position was similar to that seen in the lung. Only a slight average increase in "thoracic" compliance occurred, however, in the prone and lateral positions. In some instances there was a decrease in the "thoracic" compliance as indicated by the negative values in the range of observations.

Only the pulmonary compliance was measured in the normal subjects. In this group there was an increase in pulmonary compliance after deep breaths in each of the positions studied, including the sitting position. This occurred whether the FRC in the sitting position was the same as or larger than the supine FRC.

\footnotetext{
${ }^{3}$ Since measurements in right and left lateral positions were similar and lung yolumes in these two positions are comparable (10), these data have been pooled.
}

The pulmonary compliances obtained in the normal subjects were considerably greater than those obtained in the patients in comparable body positions. The values for the subjects were 2.6 to 3.1 times greater than those obtained in the patients, even when differences in height were taken into account.

Since the foregoing results were obtained after maximally deep breaths it was of interest to determine whether this change occurred at a critical volume (or pressure) or whether it showed a gradual and progressive increase. Five subjects and two patients were studied to investigate this question. The pulmonary compliance in the tidal volume range was measured after each series of progressively deeper breaths. The results in the individuals studied are shown in Figure 3 where the percentage increase in compliance is plotted against the volumes inhaled prior to the measurement of the compliance. The intercepts on the abscissa represent the average tidal volumes accepted by the individuals during the period of quiet breathing. In all but one instance there was a progressive increase in the pulmonary compliance with progressively deeper breaths. The degree of change, however, showed considerable individual variation.

To determine how promptly the increase in 


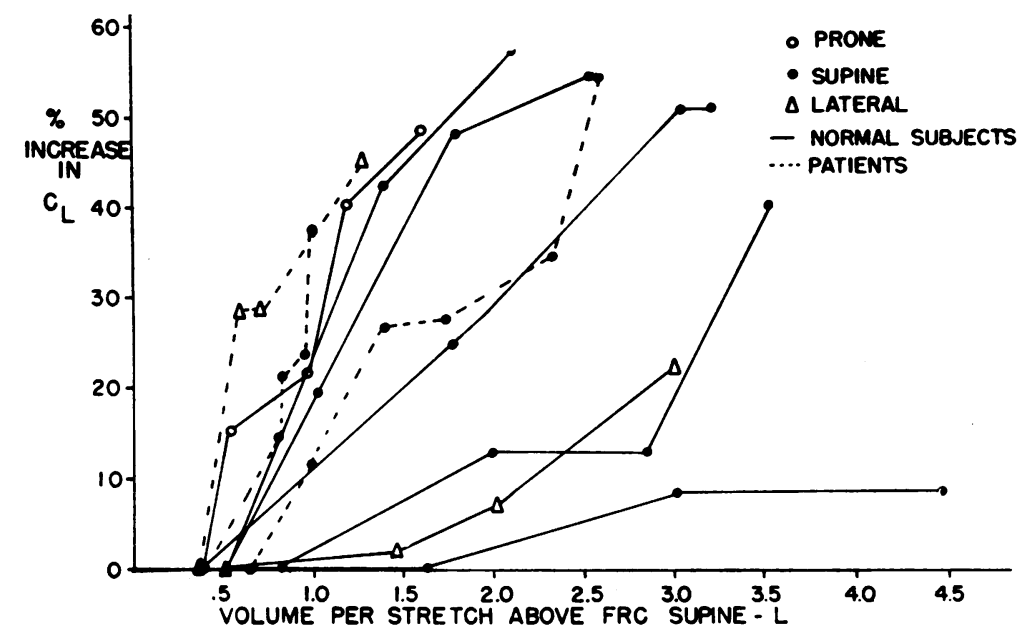

Fig. 3. Effect of Progressively Deeper Breaths on Pulmonary Compliance $\left(\mathrm{C}_{\mathbf{L}}\right)$

compliance could be reversed, forced expirations below the resting end-expiratory position were performed. This was done immediately after the measurement of compliance following a series of maximally deep inspirations. This maneuver was attempted in two of the patients, but the positive tank pressures obtained ( 10 to $15 \mathrm{~cm} . \mathrm{H}_{2} \mathrm{O}$ ) were insufficient to produce a change in pulmonary compliance. In five normal subjects, however, spontaneous forced expirations to the residual volume produced a prompt and marked decrease in the pulmonary compliance and a return of the pulmonary compliance close to the lowest value previously obtained.

\section{DISCUSSION}

In the process of collecting the data it was apparent that there was considerable variability from day to day on the same individual. This amounted to 12 to 20 per cent in the "control" values of pulmonary compliance and occurred despite the use of essentially the same technique. It was thought that much of this variability was due to variations in esophageal "tone." For example, after a deep breath there was occasionally obvious evidence of esophageal activity which was manifested by failure of the esophageal pressure change to follow the lung volume changes. At other times there was a shift in the resting end-expiratory esophageal pressure either to a more negative or to a more positive value. In six instances, involving five normals and one patient, studies were rejected because of extreme variations of this type. Except for one normal subject all were repeat studies. Much difficulty was encountered in passing the esophageal balloon in the single study on the normal subject and there was obvious esophageal activity. The compliance values obtained in these rejected studies revealed four normal subjects with extremely high lung compliances ( 0.4 to 0.5 L. per $\mathrm{cm} . \mathrm{H}_{2} \mathrm{O}$ ) ; deep breaths produced relative increases in lung compliance comparable to the values reported. In two other instances deep breaths produced essentially no change in pulmonary compliance. One of these was the single study on the normal subject. This was contrary to the usual observations seen in the other individuals. When all the rejected data were included, the average increase in the different body positions was not significantly different from the values reported.

It was anticipated that the more rapid fall in compliance observed in the normal subjects might be related to the tidal volumes or breathing frequency. Tidal volumes ranged from 500 to 1,200 $\mathrm{ml}$. in the normal subjects and from 200 to 650 $\mathrm{ml}$. in the patients. No relationship between tidal volume and rate of fall could be demonstrated, even when the tidal volume was expressed as per cent of vital capacity in the subjects or per cent of predicted vital capacity in the patients. Frequencies of breathing in the normal subjects 
ranged from 9 to 16 per minute and in the patients from 14 to 18 per minute. No consistent relationship between rate of fall and respiratory frequency was shown.

From these results it appears that during quiet or shallow breathing after a series of deep breaths there was a decrease in the pulmonary compliance in both normal subjects and poliomyelitic patients. This change could have been due to a number of factors ; for example, there may have been changes in the pressures recorded in the esophagus due to hysteresis of mediastinal contents; there may have been closure of units within the lungs so that the effective volume was less; there may have been an alteration of the surface forces which could have resulted in the closure of pulmonary units; or a change in surface forces might produce a change in pulmonary compliance without causing closure of pulmonary units.

This change in pulmonary compliance appears to be real and not due to hysteresis of mediastinal contents or other artifacts associated with using esophageal pressure as an index of intrapleural pressure. This is supported by the observations that similar changes in pulmonary compliance occurred in a variety of body positions in which artifacts resulting from using esophageal pressure would be minimized. Furthermore, changes were observed in the lungs plus "thorax" in patients in whom no esophageal pressures were used.

Whether there was closure of units cannot be decided from these data. The functional residual capacity was measured in the supine position before and after stretching in eight patients, but no significant difference was found between the two series. The time required to make the measurements was 15 to 20 minutes. This time period would have been sufficient for any increase in the FRC to have reverted in the normal subjects since they showed a fall in pulmonary compliance over a comparable interval of time. On the other hand, the patients did not show a prompt fall in compliance and a closure of pulmonary units would not seem to have occurred. The other and more likely probability is that the helium method used did not have sufficient sensitivity to detect a small difference in the FRC. Comparison of paired measurements of the functional residual capacity on supine patients and upright subjects has shown a variation of \pm 6 per cent. There is also the pos- sibility that no change in lung volume occurred, although this would be contrary to the findings on anesthetized dogs in which small but significant differences were found (4). The resting end-expiratory esophageal pressure showed so much variability probably due to alterations in esophageal "tone," that it was not possible to use it as an index of altered lung volume after maximal deep breaths.

How much of this change resulted from closure of units and how much resulted from an alteration in surface forces is not clear. Since these changes are similar to those noted in other experimental animals $(4,11)$ it is perhaps reasonable to apply conclusions from such studies to human beings. If this is done, then the changes in compliance would be explained on the basis of both phenomena, a closure of some units, and an alteration in surface forces in others. One might conjecture that sighing may be an expression of a reflex mechanism which attempts to correct these changes and make the lungs more compliant.

One can also conclude that when deep breaths produce an increase in pulmonary compliance they are beneficial since less energy will be required for breathing in the tidal volume range; and to the extent that there is a more uniform distribution of open alveoli there will be a better distribution of gas within the lungs. It is pertinent to point out that deep breathing should minimize the changes in pulmonary compliance associated with severe respiratory muscular weakness due to poliomyelitis provided it was done sufficiently often. Furthermore, spontaneous or assisted deep breaths during postoperative recovery might minimize the occurrence of atelectasis.

\section{SUMMARY}

Convalescent poliomyelitic patients and normal subjects showed a decrease in their pulmonary compliance as measured in the tidal volume range during quiet breathing after a series of deep breaths. This change occurred in the prone, supine, lateral and sitting positions. Compliance decreased 26 to 40 per cent. Two or more deep breaths to the limit of inspiration, after the period of quiet breathing, produced an increase in the compliance; this increase could be eliminated by forced expirations in the normal subjects. It was thought that these changes were probably due to 
the opening and closing of various units within the lung.

\section{ACKNOWLEDGMENT}

The authors wish to acknowledge the helpful criticism and advice of Drs. J. L. Whittenberger and J. Mead.

\section{REFERENCES}

1. Ferris, B. G., Jr., Mead, J., Whittenberger, J. L., and Saxton, G. A., Jr. Pulmonary function in convalescent poliomyelitic patients. III. Compliance of the lungs and thorax. New Engl. J. Med. 1952, 247, 390.

2. Wu, N., Miller, W. F., and Luhn, N. R. Studies of breathing in anesthesia. Anesthesiology 1956, 17, 696.

3. Cherniack, R. M., Adamson, J. D., and Hildes, J. A. Compliance of the lungs and thorax in poliomyelitis. J. appl. Physiol. 1955, 7, 375.

4. Mead, J., and Collier, C. Relation of volume history of lungs to respiratory mechanics in anesthetized dogs. J. appl. Physiol. 1959, 14, 669.
5. Shambaugh, G. E., Jr., Harrison, W. G., Jr., and Farrell, J. I. Treatment of respiratory paralysis of poliomyelitis in a respiratory chamber. J. Amer. med. Ass. 1930, 94, 1371.

6. Ferris, B. G., Jr., and Kriete, B. C. Unpublished data.

7. Mead, J., McIlroy, M. B., Selverstone, N. J., and Kriete, B. C. Measurement of intraesophageal pressure. J. appl. Physiol. 1955, 7, 491.

8. Ferris, B. G., Jr., Mead, J., and Frank, N. R. Effect of body position on esophageal pressure and measurement of pulmonary compliance. J. appl. Physiol. 1959, 14, 521.

9. Gilson, J. C., and Hugh-Jones, P. The measurement of the total lung volume and breathing capacity. Clin. Sci. 1949, 7, 185.

10. Svanberg, L. Influence of posture on the lung volumes, ventilation and circulation in normals. A spirometric-bronchospirometric investigation. Scand. J. clin. Lab. Invest. 1957, 9, suppl. 25.

11. Bernstein, L. Elastic pressure-volume curves of the lungs and thorax of the living rabbit. J. Physiol. (Lond.) 1957, 138, 473. 